\title{
Hyperenteroglucagonaemia and small intestinal mucosal growth after colonic perfusion of glucose in rats
}

\author{
B M MIAZZA, M Y T AL-MUKHTAR, M SALMERON, M A GHATEI, \\ M FELCE-DACHEZ, A FILALI, R VILLET, N A WRIGHT, \\ S R BLOOM, AND J-C RAMBAUD
}

From the Research Unit on Pathophysiology of Digestion (INSERM U54) Hopital Saint-Lazare, Paris, France, Departments of Medicine and Histopathology, Royal Postgraduate Medical School, London, United Kingdom, Departments of Pathology and of Surgery, Hôpital Lariboisière, Paris, France

SUMMARY Beside intraluminal factors, humoral agents play an important role in intestinal adaptation. Enteroglucagon, the mucosal concentration of which is maximal in the terminal ileum and colon, is the strongest candidate for the role of small intestinal mucosal growth factor. The present experiment was designed to study the role of colonic enteroglucagon in stimulatiing mucosal growth in rats with a normal small intestine. After eight days of glucose large bowel perfusion, enteroglucagon plasma concentrations were $120 \cdot 7 \pm$ SEM $9 \cdot 2 \mathrm{pmol} / \mathrm{l}$, versus $60 \cdot 1 \pm 6 \cdot 8$ in mannitol perfused control rats $(\mathrm{p}<0.001)$. Gastrin, cholecystokinin, neurotensin, pancreatic glucagon, and insulin plasma concentrations were unchanged. Crypt cell proliferation, measured by the vincristine metaphase arrest technique, increased significantly in the small intestine of glucose perfused animals $(\mathrm{p}<0.005-0.001)$ in comparison with the controls. This resulted in a greater mucosal mass in both proximal and distal small bowel: mucosal wet weight, DNA, protein and $\alpha \mathrm{D}$-glucosidase per unit length intestine were all significantly higher $(\mathrm{p}<0.05-0 \cdot 001)$ than in mannitol perfused rats. Our data, therefore, support the hypothesis that enteroglucagon is an enterotrophic factor and stress the possible role of the colon in the regulation of small bowel trophicity.

The large bowel mucosa is rich in endocrine cells. ${ }^{1-5}$ It is tempting to speculate as to whether these cells, triggered by unabsorbed nutrients, participate in a feed-back control of upper gastrointestinal functions. Acute intracolonic infusion of some nutrients does induce inhibition of gastric ${ }^{67}$ and pancreatic exocrine ${ }^{8}$ secretions. Another possible role for the colon as an endocrine organ could be a trophic action on the small intestine. Indeed, colonic mucosa has, after the ileum, the highest content of glucagon-like immunoreactivity both in $\operatorname{man}^{9}$ and in rats, ${ }^{10}$ and enteroglucagon is currently the strongest candidate as a small intestinal mucosal growth factor (enterotrophin). ${ }^{11} 12$ Moreover, in rats with $50 \%$ and $90 \%$ ileal resection, which induces a mild but significant structural and functional adaptation of the residual proximal small intestine, ${ }^{13}$ entero-

Address for correspondence: Dr Jean-Claude Rambaud, Unité de Recherches sur la Physiopathologie de la Digestion. Inserm U54 - Hôpital Saint-Lazare 107bis. rue du faubourg Saint-Denis 75475 Paris CEDEX 10. France.

Received for publication 22 June 1984 glucagon is significantly increased both in blood and in colonic mucosa. ${ }^{13}$ In this model, small intestinal absorption is impaired, and a direct effect of a compensatory increase in food intake on the stimulation of mucosal growth of the residual small bowel has been suggested. ${ }^{14}$

The present experiment was an attempt to study further the role of colonic enteroglucagon as an enterotrophin by using an experimental model which maintains small intestinal integrity. Glucose perfusion of the large bowel was used to trigger enteroglucagon release, as it has been shown to induce hyperenteroglucagonemia in man. ${ }^{6}$

\section{Methods}

\section{STUDY DESIGN}

Male SPF wistar rats weighing 250-300 g were used. After a short laparotomy under pentobarbital anaesthesia (Nembutal Abbott, $4 \mathrm{mg} / 100 \mathrm{~g}$ body weight), a vinyl tube (Portex Ltd) (id 1.0, od 2.0 
$\mathrm{mm}$ ) was inserted into the caecum. Its proximal end was pulled subcutaneously to the interscapular area, where it was connected to the perfusion system, attached to the rat by a dorsal harness. Solutions were infused at a flow rate of $1.8 \mathrm{ml} / \mathrm{h}$ by a constant peristaltic pump (Neotechnique, France). The animals could move freely in individual cages and had free access to food and water. Cages had a wire netting bottom allowing the passage of stools and urine to an underlying tray.

Non-fasted rats were killed after eight days of continuous intracaecal perfusion of $10 \%$ glucose (osmolality $555 \mathrm{mOsm} / \mathrm{kg})(\mathrm{n}=10)$. The resultant changes in plasma concentrations of several peptides, in intestinal cell proliferation (Crypt cell production rats $=C C P R$ ) and in small intestinal structure and function (see below) were compared with those found in $10 \%$ mannitol (osmolality 550 $\mathrm{mOsm} / \mathrm{kg})(\mathrm{n}=8)$ perfused control animals.

In all rats, 4-6 $\mathrm{ml}$ blood were taken by cardiac puncture in heparinised tubes, containing also $0 \cdot 2$ ml aprotinin (Iniprol, Laboratoires Choay, France). The plasma was then separated by centrifugation and stored at $-70^{\circ} \mathrm{C}$ until assay. At 0900 on the day they were killed, 10 glucose and eight mannitol perfused rats received vincristine sulphate (Oncovin, Lilly) at a dose of $1 \mathrm{mg} / \mathrm{kg}$ by intraperitoneal injection. The first rat in each group was killed 30 minutes after vincristine administration, the remaining animals were killed at 15 minute intervals thereafter. The whole intestinal tract, and the liver, pancreas and kidneys were then removed. The intestine was stripped of its mesentery and its contents washed out with ice cold isotonic saline. Six $2 \mathrm{~cm}$ samples were taken for CCPR measurement at sites $10,25,50,75$, and $90 \%$ of the small bowel length (measured between the pylorus and the ileocaecal valve) and in the distal colon ( $3 \mathrm{~cm}$ above the rectum); two rats in the glucose group were subsequently discarded because of inaccurate vincristine injection. Two samples (adjacent to sites $10 \%$ and $75 \%$ ) were also taken for morphometry and fixed in Bouin's solution. Approximately $10 \mathrm{~cm}$ segments of jejunum (lying between sites 10 and $25 \%$ ) and of ileum (75 to $90 \%$ of gut length) were sectioned and measured under $5 \mathrm{~g}$ tension. The mucosa was then scraped, weighed, and deep frozen $\left(-70^{\circ} \mathrm{C}\right)$. Pancreases were carefully dissected free and weighed, as were livers and kidneys.

In order to establish that the colonic perfusate did not reflux into the small intestine, five animals were infused with either $10 \%$ glucose or $10 \%$ mannitol, containing a non-absorbable water soluble marker $\left({ }^{14} \mathrm{C}\right.$-polyethylene glycol (PEG- $\left.{ }^{14} \mathrm{C}\right), \mathrm{MW} 4000,10$ $\mu \mathrm{Ci} / \mathrm{l})$. The radioactivity of the total caecal content was measured by scintillation counting and compared with that found in $10 \mathrm{~cm}$ segments of distal ileum and proximal jejunum. Results showed that the radioactivity in the small intestine was 1-2 orders of magnitude less than in the caecum $(p<0 \cdot 001)$. Furthermore, there was no significant difference between jejunal and ileal radioactivity. The presence of significant amount of ${ }^{14} \mathrm{C}$-PEG in the small bowel was very likely caused by coprophagia, which could not be totally avoided, because all animals had diarrhoeic stools soiling the wire netting floor of the cages. In agreement with these findings, the appearance of small intestinal contents was normal in all control and experimental animals, in contrast with the watery appearance of the colonic contents.

\section{HORMONAL STUDY}

Pancreatic glucagon and enteroglucagon were measured using two different antibodies to porcine pancreatic glucagon. ${ }^{15}$ Total (gut and pancreatic) glucagon immunoreactivity was measured first using an antibody reacting with the $\mathrm{N}$-terminal region of both peptides. Pancreatic glucagon was measured separately with a specific antibody to the C-terminal portion of the peptide. Enteroglucagon plasma concentrations were then obtained by substracting pancreatic from total glucagon immunoreactivity. Gastrin and cholecystokinin were measured using two antiserea. ${ }^{16}$ One was directed to the C-terminal region, fully and equally cross reacting with both CCK and gastrin, the other was specific for the C-terminal region of the molecular form of gastrin G17. Cholecystokinin plasma concentrations were then obtained by subtracting G17 from total CCK plus gastrin immunoreactivity. Neurotensin ${ }^{17}$ and insulin ${ }^{18}$ were also measured by specific radioimmunoassays.

\section{CRYPT CELL PRODUCTION RATE (CCPR)}

Tissues were fixed in Carnoy's fluid for four hours and then transferred to $70 \%$ ethanol. After rehydration, followed by hydrolysis in $\mathrm{HCl}$ for six minutes at $60^{\circ} \mathrm{C}$, the samples were stained with Feulgen's reagent. The crypts were individually dissected under the microscope. Vincristine-blocked metaphases were then counted in 10 crypts per sample. The mean metaphase counts were plotted against time after administration of the blocking agent. The crypt cell production rate per hour for each sampling site and in each group was given by the slope of the regression line fitted by the method of least squares. ${ }^{19}$

BIOCHEMICAL DATA

Small intestinal mucosa was homogenised in ice cold isotonic saline (Ultra-Turrax homogeniser, Janke 
and Kunkel, FGR). After appropriate dilution, $\alpha$-D-glucosidase activity was assayed fluorometrically, ${ }^{20}$ DNA was measured according to Prasad et $a l^{21}$ and protein was estimated by the method of Lowry et al. ${ }^{22}$

\section{MORPHOMETRY}

Tissues were stained with haematoxylin and eosin for the measurements of villus height, crypt depth, and total mucosal thickness. The results were the mean reading of 10 well orientated villi and crypts in each section and expressed in microns.

STATISTICAL ANALYSIS

Results are expressed as mean values \pm SEM. The significance of the differences between mean values was tested by paired or unpaired Student's $t$ test, as appropriate.

\section{Results}

BODY, PANCREAS, LIVER, AND KIDNEY WEIGHTS These results are shown in the Table. After eight days of continuous colonic perfusion, all animals appeared healthy. There were small and statistically non-significant variations in body weight in both glucose and mannitol rats. Glucose perfusion provoked no change in the weight of pancreas, liver and kidneys, in comparison with mannitol perfused animals.

\section{HORMONES}

Non-fasting plasma concentrations of enteroglucagon, gastrin, cholecystokinin, and insulin are shown in Figure 1. After glucose perfusion, enteroglucagon plasma concentrations were significantly higher $(p<0.001)$ than in the controls. In contrast, gastrin, cholecystokinin, pancreatic glucagon, neurotensin, and insulin plasma concentrations were not significantly influenced by colonic perfusion of

Table Total body, pancreas, liver and kidney weights before and after 8 days of mannitol $(n=8)$ or glucose $(n=10)$ large bowel perfusion

\begin{tabular}{lccc}
\hline & Mannitol & & Glucose \\
\hline Initial body weight (g) & $276 \cdot 3 \pm 5 \cdot 5$ & ns & $273 \cdot 7 \pm 7 \cdot 1$ \\
& $\uparrow$ & & $\uparrow$ \\
& $n$ & & $n s$ \\
Final body weight $(\mathrm{g})$ & $263 \cdot 9 \pm 5 \cdot 8$ & $\mathrm{~ns}$ & $278 \cdot 7 \pm 5 \cdot 2$ \\
Pancreas (g) & $1 \cdot 19 \pm 0 \cdot 04$ & $\mathrm{~ns}$ & $1 \cdot 13 \pm 0 \cdot 04$ \\
Liver $(\mathrm{g})$ & $11 \cdot 2 \pm 0 \cdot 2$ & $\mathrm{~ns}$ & $10 \cdot 4 \pm 0 \cdot 3$ \\
Kidneys $(\mathrm{g})$ & $2 \cdot 1 \pm 0 \cdot 1$ & $\mathrm{~ns}$ & $2 \cdot 1 \pm 0 \cdot 1$ \\
\hline
\end{tabular}

Results are mean \pm SEM; ns denotes no statistically significant differences.
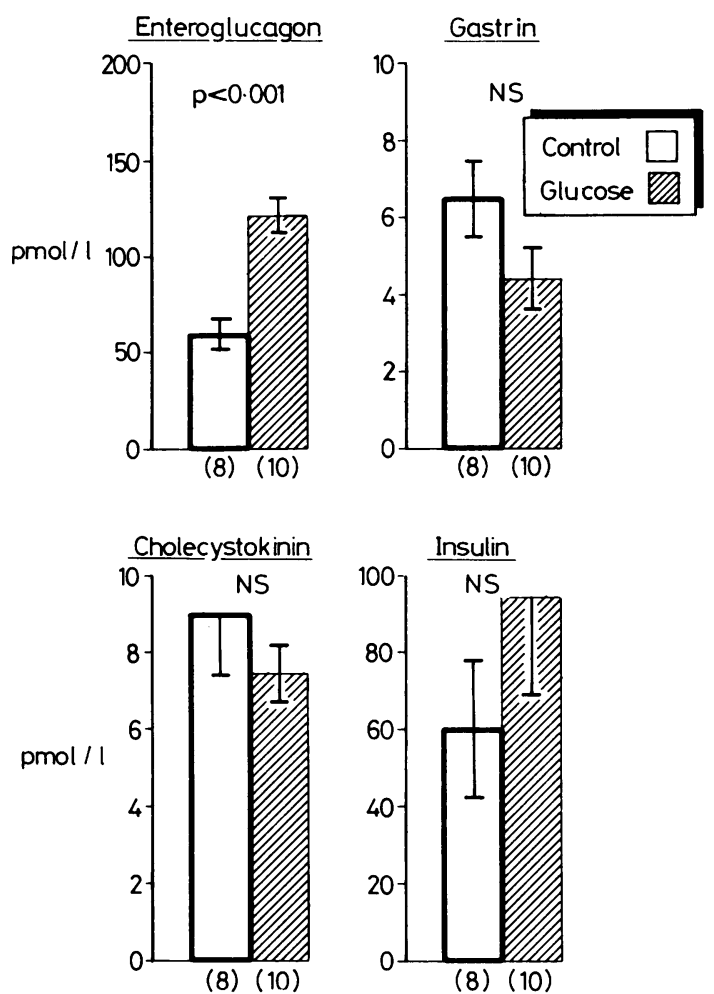

Fig. 1 Plasma concentrations of enteroglucagon, gastrin, $C C K$ and insulin in controls and glucose perfused rats. Number of animals in each group is indicated at the base of each column. NS denotes no significant difference.

glucose. Pancreatic glucagon and neurotensin results were less than 5 and $3 \mathrm{pmol} / \mathrm{l}$ respectively, and not significantly different between controls and glucose rats; therefore they are not shown on Figure 1.

CRYPT CELL PRODUCTION RATE (CCPR)

Data for CCPR per hour in five sites of the small intestine and in the distal colon are shown in Figure 2. Crypt cell production rate per hour increased significantly $(p<0 \cdot 005-0.001)$ in sites one to four after glucose perfusion, whereas the differences did not reach statistical significance in the most distal site of the small bowel (terminal ileum) nor in the colon.

SMALL INTESTINAL STRUCTURE AND FUNCTION After eight days colonic perfusion of glucose, small intestinal mass increased significantly in both jejunum and ileum (Fig. 3). Mucosal wet weight, DNA and protein content per unit length of 


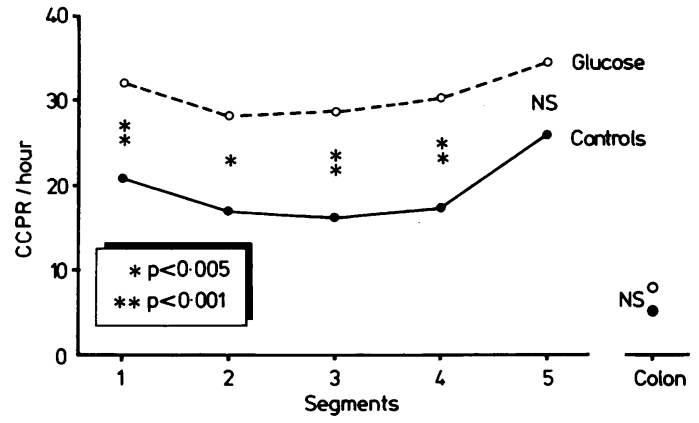

Fig. $2 C C P R / h$ in five different small intestinal segments and the colon for eight animals in each group. Segments 1-5 correspond to sites distant of 10,25, 50,75 and $90 \%$ of total small bowel length measured from the pylorus.

intestine were all greater $(\mathrm{p}<0 \cdot 05-0.001)$ than in controls. The activity of $\alpha$-D-glucosidase, expressed per unit length of small bowel, increased significantly $(\mathrm{p}<0.05-0.02)$ in both proximal and distal intestine (Fig. 4). When the results were

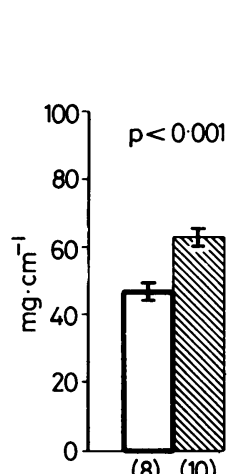

(8) (10)

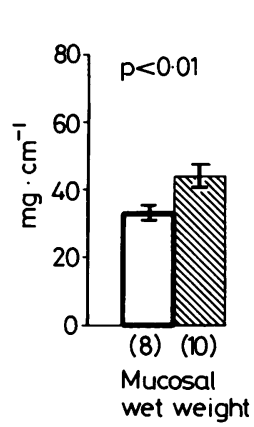

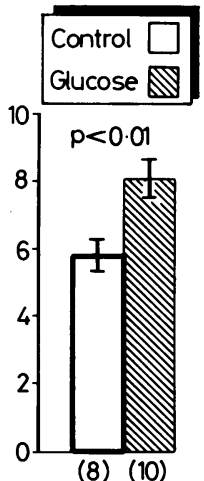

(8) $(10)$
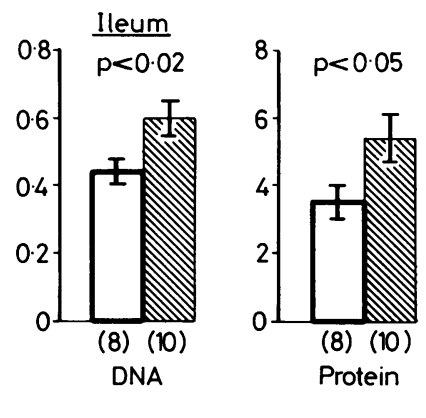

expressed per milligram DNA, $\alpha$-D-glucosidase activity was significantly greater in the ileum $(p<0.05)$ but not in the jejunum (Fig. 4). Results of quantitative histology are shown in Figure 5. Despite a trend towards longer villi, deeper crypts and a thicker mucosa, particularly in the ileum, none of these differences reached statistical significance.

\section{Discussion}

Besides the role of luminal nutrition and pancreatico-biliary secretions, ${ }^{11}$ there is good evidence that hormonal factors play a role in intestinal adaptation. Direct evidence for a humoral control was found in cross circulation experiments: $:^{23}$ small bowel resection stimulated a hyperplastic response not only in resected animals, but also in the unoperated partners of the parabiotic pairs. Similar results were observed after jejunectomy, ${ }^{25}$ jejunal exclusion, ${ }^{12}$ ileal infusion of $30 \%$ dextrose $^{26}$ and during lactation ${ }^{27}$ in intestinal segments completely isolated from the topical action of nutrients and pancreatico-biliary secretions.

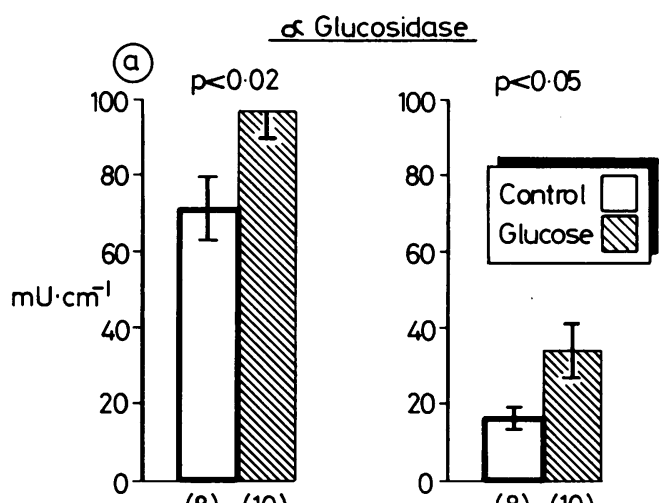

(b)

(8) $(10)$

(8) (10)

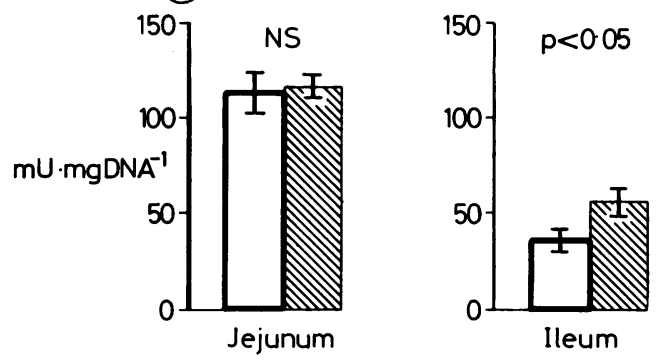

Fig. 4 D-glucosidase activity in jejunum and ileum. Panel a: $\alpha-D$-glucosidase activity per $\mathrm{cm}$ intestine. Panel b: $\alpha$-D-glucosidase activity per $\mathrm{mg} D N A$.
Fig. 3 Mucosal wet weight, DNA and protein $(\mathrm{mg} / \mathrm{cm})$ in jejunum and ileum. 


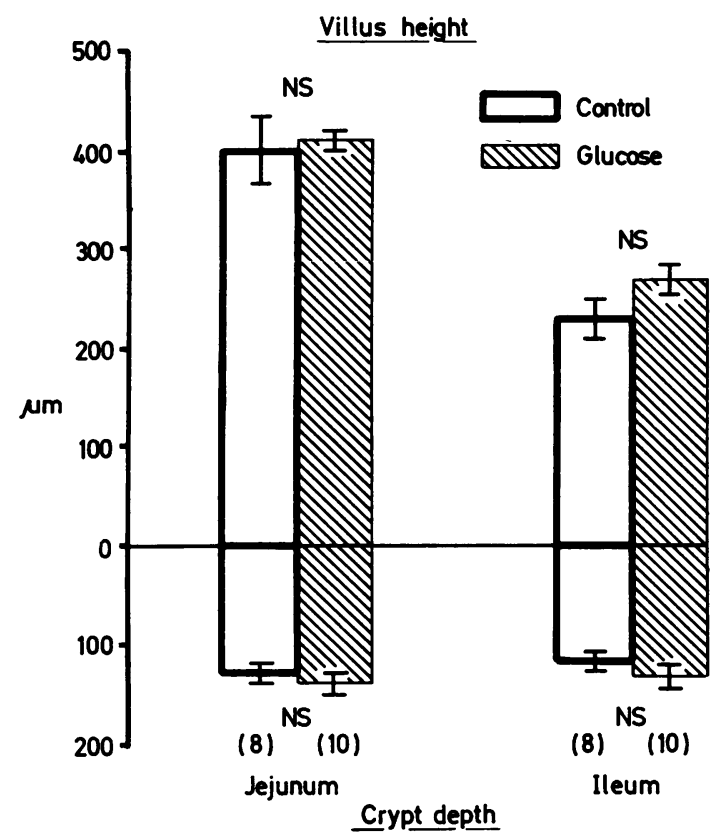

Fig. 5 Quantitative histology in jejunum and ileum showing villus height above, and crypt depth below the horizontal axis.

The potential role of some hormones has been investigated. Gastrin can be trophic to the duodenum, ${ }^{28}$ but not to the rest of the small intestine. ${ }^{28} 29$ The administration of cholecystokinin plus secretin prevented the mucosal hypoplasia of total parenteral nutrition both in dogs ${ }^{30}$ and rats. ${ }^{31}$ An indirect action, however, mediated through the secretions of liver and pancreas, is more likely than a direct enterotrophic effect. ${ }^{32}$ Several recent studies $^{13}{ }^{33-38}$ have shown that in various situations where intestinal adaptation occurs, circulating enteroglucagon concentrations are raised.

The present experiment was an attempt to study further the possible role of colonic enteroglucagon as a mucosal growth factor, in an animal model which maintained small bowel integrity. We stimulated enteroglucagon release from its endocrine cells by perfusing the colon with a glucose solution. Our working hypothesis was that if enteroglucagon is enterotrophic, we should be able to show changes in cellular proliferation and possibly in mucosal mass in the small intestine, at a distance, and therefore without contact with the colonic perfusate. This is indeed what we found.

In agreement with the findings of a previous study in man, ${ }^{6}$ colonic perfusion of glucose provoked a two-fold increase in enteroglucagon blood levels compared with mannitol controls. The possibility of a reflux of glucose in the distal intestine, which is rich in enteroglucagon cells, ${ }^{13}$ was excluded by inspection of small and large bowel contents and by experiments in which $\mathrm{PEG}-{ }^{14} \mathrm{C}$ was added to the colonic perfusion solution. As enteroglucagon was measured only eight days after starting the perfusion, it could be argued that it was not released by the colon but by the hyperplastic small bowel. Against this hypothesis is the fact that the small intestinal hormone cholecystokinin was not increased. Of course, we cannot exclude the possibility that glucose may have released other colonic regulatory peptides or amines such as serotonin, vasoactive intestinal peptide, somatostatin, ${ }^{12}{ }^{2}$ pancreatic polypeptide, ${ }^{5}$ and peptide YY which is especially abundant in the rat large bowel mucosa. ${ }^{3}$ None of these substances have been considered until now as a putative enterotrophic factor.

Crypt cell production rate and indices of mucosal mass (mucosal wet weight, DNA and protein per unit length of intestine) were increased by large bowel glucose perfusion, when compared with mannitol treated controls. The increase in CCPR was not statistically significant in the most distal small intestine site. This last finding is further evidence against reflux of glucose into the distal ileum, as an intraluminal glucose load at this site should have induced mucosal growth. It is noteworthy that the effect of large bowel glucose perfusion seems specific for the small intestine, because colonic CCPR was unaffected and no change was found in the weight of pancreas, liver and kidneys; however, the stomach was not studied. The absence of effect on pancreatic weight support the suggestion that enteroglucagon does not mediate the pancreatic hyperplasia observed after transposition of the proximal jejunum between the stomach and the duodenum. ${ }^{38}$

A similar pattern of results was found for $\alpha$-Dglucosidase activity, when expressed per unit length intestine. Changes in enzyme specific activity, however, could only be detected in the ileum. The results for quantitative histology were somewhat disappointing. Despite the tendency towards greater values after colonic glucose perfusion, none of the values were significantly different. This was caused in part by the large scatter of the results in both experimental and control groups, but also probably by the inaccuracy of this technique in detecting small alterations. ${ }^{39}$ Indeed, it must be stressed that the changes in mucosal mass after large bowel perfusion of glucose were relatively small - approximately $30 \%$ increases above the control values. In this respect our results are similar to those observed 
after ileal resection ${ }^{40}$ whereas the ileal hyperplasia induced by proximal small intestinal resection is much more marked. ${ }^{11}$ As the rise in enteroglucagon plasma concentrations is equivalent in both types of resection, ${ }^{13}$ the greater enterotrophic action of jejunectomy could be accounted for by differences in luminal factors. We did not measure food intake in our study. Hyperphagia was very unlikely, however, because body weight did not significantly vary in both experimental and control animals. Moreover a putative hyperphagia secondary to diarrhoea should have happened in both mannitol and glucose rats, and thus cannot explain the difference in small bowel mucosa growth between the two animal groups. The absence of weight gain during the perfusion period was in fact probably because of decreased ingesta, secondary either to the stress of experimental conditions, or perhaps to a specific inhibition of appetite by the colonic glucose and mannitol perfusion.

Finally, the present experiment indicates that the colon is capable of influencing not only gastric ${ }^{67}$ and pancreatic ${ }^{8}$ functions, but also epithelial cell renew$\mathrm{al}$ in the small intestine. Whether this is a physiological function remains to be established, as glucose is not delivered in significant amounts to the normal colon. Preliminary experiments have also shown that twice daily starch or oleic acid instillation in the rat colon for eight days induces an increase in jejunal mucosal weight (unpublished), though the amounts administered were markedly higher than those probably entering the colon during normal feeding.

This paper was presented at the Autumn Meeting of the British Society of Gastroenterology held in Leeds in September 1982. The authors thank Mrs I Wohnlich for her bibliographic assistance and Mrs I Batby for typing the manuscript.

\section{References}

1 Larsson LI. Gastrointestinal cells producing endocrine, neurocrine and paracrine messengers. Clin Gastroenterol 1980; 9: 485-516.

2 Debas HT. The colon as an endocrine organ. Dig Dis Sci 1981; 26: 193-4.

3 Lundberg JM, Tatemoto K, Terenius L et al: Localization of the polypeptide YY (PYY) in gastrointestinal endocrine cells and effects on intestinal blood flow and motility. Proc Natl Acad Sci USA 1982; 79: 4471-5.

4 Höfler H, Kasper M, Heitz PhU. The neuroendocrine system of normal human appendix, ileum and colon, and in neurogenic appendicopathy. Virchows Arch [Pathol Anat] 1983; 399: 127-140.
5 El-Salhy M, Grimelius L, Wilander E et al. Immunocytochemical identification of polypeptide YY (PYY) cells in the human gastrointestinal tract. Histochemistry 1983; 77: 15-23.

6 Jian R, Besterman HS, Sarson DL et al. Colonic inhibition of gastric secretion in man. Dig Dis Sci 1981; 26: 195-201.

7 Seal AM, Debas HT. Colonic inhibition of gastric acid secretion in the dog. Gastroenterology 1980; 79: 823-7.

8 Harper AA, Hood AJC, Mushens J, Smy JR. Inhibition of external pancreatic secretion by intracolonic and intraileal infusions in the cat. $J$ Physiol 1979; 292: 445-54.

9 Ghatei MA, Bloom R. Enteroglucagon in man. In: Bloom SR, Polak JM, eds. Gut hormones. Edinburgh: Churchill Livingstone, 1981: 332-8.

10 Bloom SR. Glucagon: Pancreatic and enteric. In: Chey W, Brooks FP, eds. Endocrinology of the gut. Thorofare, New Jersey: Charles B. Slack, 1974: 88-102.

11 Dowling RH. Small bowel adaptation and its regulation. Adaptation pathophysiology of intestinal response to disease. Scand J Gastroenterol 1982; 17: suppl 74: 53-74.

12 Sagor GR, Chatei MA, Al-Mukhtar MYT, Wright NA, Bloom SR. Evidence for a humoral mechanism after small intestinal resection. Exclusion of gastrin but not enteroglucagon. Gastroenterology 1983; 84: 902-6.

13 Gregor M, Bryant MG, Buchan AMJ et al. Effect of intestinal resection on colonic regulatory peptides in the rats: In: Robinson JWL, Dowling RH, Riecken ED, eds. Mechanisms of intestinal adaptation. Lancaster: MTP Press, 1982: 549-54.

14 Menge $\mathrm{H}$, Gräfe $\mathrm{M}$, Lorenz-Meyer $\mathrm{H}$ et al. The influence of food intake on the development of structural and functional adaptation following ileal resection in the rat. Gut 1975; 16: 468-72.

15 Ghatei MA, Uttenthal LO, Bryant MG, Christofides ND, Moody AJ, Bloom SR. Molecular forms of glucagon like immunoreactivity in porcine intestine and pancreas. Endocrinology 1983; 112: 917-23.

16 Adrian TE, Bacarese-Hamilton IJ. Cholecystokinin. In: Bloom SR, Long RJ, eds. Radioimmunoassay of gut regulatory peptides. London: Saunders, 1982: 60-5.

17 Blackburn AM, Bloom SR. A radioimmunoassay for neurotensin in human plasma. $J$ Endocrinol 1979; 83: 175-81.

18 Albano JDM, Ekins RP, Maritz G, Turner RC. A sensitive precise radioimmunoassay of serum insulin relying on charcoal separation of bound and free hormone moieties. Acta Endocrinol 1972; 70: 487-509.

19 Wright NA, Appleton DR. The metaphase arrest technique. A critical review. Cell Tiss Kinet 1980; 13: 643-62.

20 Peters TJ, Heath JR, Wansbrough-Jones MH, Doe WF. Enzyme activities and properties of lysosomes and brush borders in jejunal biopsies from control subjects and patients with coeliac disease. Clin Sci Mol Med 1975; 48: 259-67.

21 Prasad AS, Dumouchelle E, Koniuch D, Oberleas D. A simple fluorometric method for the determination of RNA and DNA in tissues. J Lab Clin Med 1972; 80: 598-602. 
22 Lowry OH, Rosenbrough NJ, Farr AL, Randall RJ Protein measurement with the Folin-Phenol reagent. $J$ Biol Chem 1951; 193: 265-75.

23 Laplace JP. Sur l'existence éventuelle d'un facteur circulant, intervenant dans le déterminisme de l'augmentation pondérale du tissu intestinal restant après une résection limitée d'intestin grêle. Etude chez le porcelet par circulation sanguine croisée. Rec Méd Vét 1972; 148: 931-47.

24 Williamson RCN, Buchholtz TW, Malt RA. Humoral stimulation of cell proliferation in small bowel after transection and resection in rats. Gastroenterology 1978; 75: 249-54.

25 Williamson RCN, Bauer FLR. Evidence for an enterotropic hormone: compensatory hyperplasia in defunctioned bowel. Br J Surg 1978; 65: 736-9.

26 Spector MH, Levne GM, Deren JJ. Direct and indirect effects of dextrose and amino acids on gut mass. Gastroenterology 1977; 72: 706-10.

27 Elias E, Dowling RH. The mechanism for small-bowel adaptation in lactating rats. Clin Sci Mol Med 1976; 51: 427-33.

28 Johnson LR, Lichtenberger LM, Copeland EM, Dudrick SJ, Castro GA. Action of gastrin on gastrointestinal structure and functon. Gastroenterology 1975; 68: 1184-92.

29 Oscarson JEA, Veen HF, Williamson RCN, Ross JS, Malt RA. Compensatory post resectional hyperplasia and starvation atrophy in small bowel: dissociation from endogenous gastrin levels. Gastroenterology 1977; 72: $890-5$.

30 Hughes CA, Bates T, Dowling RH. Cholecystokinin and secretin prevent the intestinal mucosal hypoplasia of total parenteral nutrition in the dog. Gastroenterology 1978; 75: 34-41.

31 Hughes CA, Breuer RS, Ducker DA, Hatoff DE, Dowling $\mathrm{RH}$. The effect of cholecystokinin and secretin on intestinal and pancreatic structure and function. In: Robinson JWL, Dowling RH, Riecken EO, eds. Mechanisms of intestinal adaptation.
Lancaster: MTP Press, 1982: 435-50.

32 Levine GM, Fine $H$, Shiau YF. Effects of cholecystokinin-octapeptide and secretin on intestinal structure and function. [Abstract] Gastroenterology 1981; 80: 1209.

33 Jacobs LR, Bloom S, Harsoulis P, Dowling RH. Intestinal adaptation in hypothermic hyperplasia. [Abstract] Clin Sci Mol Med 1975; 48: 14P.

34 Gregor M, Bryant MG, Buchan AMJ, Bloom SR, Polak JM. Effects of intestinal resection in enteroglucagon in rats. [Abstract] Gut 1980; 21: A907.

35 Jacobs LR, Bloom SR, Dowling RH. Response of plasma and tissue levels of enteroglucagon immunoreactivity to intestinal resection, lactation and hyperplasia. Life Sci 1981; 29: 2003-7.

36 Sagor GR, Al-Mukhtar MYT, Ghatei MA, Wright NA, Bloom SR. The effect of altered luminal nutrition on cellular proliferation and plasma concentrations of enteroglucagon and gastrin after small bowel resection in the rat. Br J Surg 1982; 69: 14-8.

37 Al-Mukhtar MYT, Sagor GR, Ghatei MA et al. The relationship between endogenous gastrointestinal hormones and cell proliferation in models of adaptation. In: Robinson JWL, Dowling RH, Riecken EO, eds. Mechanisms of intestinal adaptation. Lancaster: MTP Press, 1982: 243-54.

38 Miazza BM, Ghatei MA, Adrian TE, Bloom SR, Dowling $\mathrm{RH}$. Role of regulatory peptides in the small bowel and pancreatic adaptation of pancreaticobiliary diversion (PBD) following jejunal or ileal transposition in the rat. [Abstract]. Eur J Clin Inv 1982; 12: 27.

39 Al-Mukhtar MYT, Polak JM, Bloom SR, Wright NA. The search for appropriate measurements of proliferative and morphological status in studies on intestinal adaptation. In: Robinson JWL, Dowling RH, Riecken EO, eds. Mechanisms of intestinal adaptation. Lancaster: MTP Press, 1982: 3-25.

40 Dowling $\mathrm{RH}$, Booth $\mathrm{CC}$. Structural and functional changes following small intestinal resection in the rat. Clin Sci 1967; 32: 139-49. 